\title{
A REFLEXÃO-AÇÃO COMO EIXO DA FORMAÇÃO DO PROFESSOR: RELATO DE EXPERIÊNCIA EM UMA FACULDADE BILÍNGUE DE PEDAGOGIA
}

ACTION-REFLECTION AS THE AXIS OF TEACHER EDUCATION: REPORT OF AN EXPERIENCE IN A BILINGUAL PEDAGOGY FACULTY

\author{
Aline Xavier ${ }^{1}$, Maria Carmen Euler Torres ${ }^{1}$ \\ ${ }^{1}$ Instituto Nacional de Educação de Surdos (INES), Rio de Janeiro, RJ, Brasil \\ desualinexavier@gmail.com; meuler@uol.com.br
}

Recebido em: 25 abr. 2018

Aceito em: 2 jun. 2018

Resumo: Este texto é um relato de experiência de duas professoras e de estudantes do Departamento de Ensino Superior do Instituto Nacional de Educação de Surdos (DESU/INES) realizada em 2015, por ocasião das disciplinas ministradas no $5^{\circ}$ período do curso de pedagogia desta Instituição. As disciplinas "Textos e pretextos" e "Cognição, corporeidade e contexto" tinham como objetivo comum refletir sobre práticas cotidianas desenvolvidas com crianças surdas da Educação Infantil e primeiros anos do Ensino Fundamental, no que tange à leitura e formação do leitor e à importância do brincar para o desenvolvimento infantil. As disciplinas se propuseram a oportunizar aos estudantes a vivência e a reflexão da prática educacional, trabalhando com conhecimentos teórico-práticos. Partimos do princípio de que a ação e a reflexão compõem uma relação dialógica e dialética. Como proposta de avalição dos cursos, foi lançado aos estudantes o desafio de confeccionarem brinquedos, produtos literários e outros materiais pedagógicos voltados às crianças surdas e posterior atuação junto a elas no colégio de aplicação do próprio INES. Queríamos, com isso, aproximar os estudantes do seu público-alvo e abrir um diálogo com educadores, coordenadores e crianças do Departamento de Ensino Básico do INES (DEBASI). O resultado deste projeto, além da sessão de contação de histórias e brincadeiras realizadas na sala de leitura do Setor de Ensino Fundamental 1 (SEF1), foi a compreensão de que o professor deve se instrumentalizar para observar, questionar e redimensionar seu cotidiano por meio de um diálogo permanente entre a teoria e a prática.

Palavras-chave: formação docente - teoria/prática - professor-reflexivo

Abstract: This paper relates the experience of two teachers and students of the Department of Higher Education at National Institute of Deaf Education (DESU / INES) in 2015, during the realization of the disciplines "Texts and pretexts" and "Cognition, corporeity and context", taught to undergraduates of Pedagogy course. The subjects aimed at reflecting on daily practices developed with deaf children in early childhood education and the first years of Elementary School, focusing at reading and reader formation as well as the importance of playing for child development. The subjects seeked to offer students the experience and the educational practice reflection, based on theoretical-practical knowledge, considering that action and reflection are elements of a dialectical and dialogic relationship. As evaluation criteria of the courses, the students were challenged to create toys, literary products and other educational objects for deaf children and apply them at INES. Our goal was to make the students closer to their target audience and open a dialogue with educators, coordinators and children at Department of Basic Education (DEBASI/INES). The result of this Project was the consciousness that the teacher needs instruments to observe, question and resize the daily activities through a permanent dialogue between theory and practice, besides the practice of storytelling and games in the reading room of the Elementary School 1 (SEF1).

Keywords: teacher training - theory / practice - teacher-reflective

\section{Introdução}


A ideia de escrever este relato, a quatro mãos, surgiu da experiência vivida por nós, duas professoras recém-chegadas ao Departamento de Ensino Superior do INES, durante nossas aulas no primeiro semestre de 2015. Ao planejarmos nossas atividades para as duas turmas de $5^{\circ}$ período do curso de pedagogia bilíngue, percebíamos que nossos objetivos, metas, estratégias, embasamento teórico e ações se afinavam e que, se tratando dos mesmos estudantes, poderíamos realizar um trabalho em para além das fronteiras disciplinares, buscando o diálogo entre os conteúdos estabelecidos em cada uma das ementas.

O fato de não estarmos familiarizadas com o trabalho docente com surdos e com a formação de professores capazes de trabalhar com crianças surdas nos colocava em lugar privilegiado de abertura ao novo e de busca criativa por estratégias de ação junto a esse público. Nosso objetivo era promover uma aproximação dos estudantes, muitos deles com pouca ou nenhuma experiência com crianças, às situações reais para que pudessem aprender a refletir sobre a prática, à luz das referências teóricas escolhidas para as disciplinas. Entendemos ser de fundamental importância que nosso trabalho docente colaborasse com a instrumentalização dos estudantes para que aprendessem a observar, questionar e criar estratégias para redimensionar seu cotidiano. Partindo de uma proposta avaliativa que privilegiava a práxis, nossa intenção era provocar no aluno a consciência autônoma e a percepção de que, mesmo ainda estudantes, deveriam investigar, pesquisar e agir, e não apenas consumir de forma passiva a teoria apresentada durante a disciplina. Ou seja, acreditamos que, durante o curso de pedagogia - e não só na hora do estágio curricular obrigatório - o estudante deva ter oportunidades de vivenciar a prática educacional ao mesmo tempo em que reflete sobre ela.

Concordamos com Esteban \& Zaccur (2002) que “(...)a prática é o ponto de partida. Dela emergem as questões, as necessidades e as possibilidades, ou seja, a prática esboça caminhos a percorrer" (p.21) e que (...) "a teoria funciona como lentes que são postas diante dos nossos olhos, nos ajudando a enxergar o que antes não éramos capazes." (Idem, p.21).

Por isso, criamos com os alunos momentos de discussão a partir das teorias escolhidas, sempre buscando a relação com as vivências dos estudantes. Promovemos em sala jogos, debates, situações-problema, entre outros recursos que 
pudessem levá-los à reflexão teoria-prática. Ao final do semestre, como trabalho de conclusão, os estudantes tiveram o desafio de confeccionar, em grupos, jogos, brinquedos e brincadeiras que estivessem adequados a cada uma das disciplinas para a posterior vivência junto às crianças do SEF1 /DEBASI/ INES. ${ }^{1}$ Tal sugestão, incialmente trazida pelas professoras, foi acolhida com empolgação por parte dos alunos (as), alguns deles com desejo de compartilhar suas experiências de trabalho com crianças e adolescentes surdos no município do Rio de Janeiro e adjacências.

O resultado de todo esse trabalho foi a apresentação de dezesseis atividades/materiais pedagógicos - envolvendo os objetivos de cada disciplinavoltados para crianças surdas de idades que variaram entre 4 e 10 anos, cuidadosamente planejados, tendo em vista o conteúdo que seria trabalhado com as crianças-alvo, a adequação às idades, os objetivos e as melhores estratégias para cada faixa etária e período do desenvolvimento. Desses trabalhos, quatro foram levados ao DEBASI, como um projeto experimental de reativação da sala de leitura do setor, desativada há alguns anos para reformas.

Com isso, acreditamos que, além dos ganhos para os graduandos já apontados acima e para nossa experiência como docentes, (re)iniciamos um diálogo com o colégio de aplicação, ajudando a promover a aproximação entre departamentos e também sugerindo a possibilidade de reativação da sala de leitura infantil, com a possibilidade de outras atividades como essa, que auxiliarão no processo de construção de novos projetos de formação-docência-extensão.

\section{Fundamentação teórica}

A proposta de currículo de pedagogia do INES, tanto em sua modalidade presencial como a distância, apresenta como dois de seus objetivos gerais:

(i) Formar pedagogos competentes e comprometidos com posicionamentos éticos, que englobem pensamento crítico, reflexivo e criativo, por meio da construção de conhecimentos teóricos, técnicos e práticos, cujas correspondentes ações sirvam como marca de excelência e referência no país; (ii) Disponibilizar-se como espaço de discussões e revisões críticas relacionadas com a formação de educadores capacitados a atenderem diferentes necessidades e desafios próprios da sociedade brasileira.(...) (Grifos nossos)

\footnotetext{
${ }^{1}$ SEF 1/DEBASI - Setor de Ensino Fundamental 1 do departamento de Ensino Básico do Ines
} 
E como um dos objetivos específicos:

Oportunizar condições teórico-reflexivas que tornem o licenciando um real participante também no desenvolvimento do projeto político-pedagógico escolar e seja capaz de expressar e explicar a lógica de práxis educativas na perspectiva de sua contínua reconstrução, visando tornar igualmente ensinos de nossas escolas regulares públicas uma realidade de qualidade para todos; o marca de excelência e referência no país. (Grifo nosso).

Tais objetivos nos conduzem a refletir na perspectiva de uma pedagogia crítica que acredita que as escolas e espaços de formação são territórios de luta e que a pedagogia é também uma forma de política cultural. A pedagogia crítica propõe uma educação capaz de ampliar as capacidades humanas a fim de habilitar as pessoas a intervir na formação de suas próprias subjetividades. (GIROUX \& SIMON, 2014).

Neste sentido, teoria e prática são igualmente valorizadas de modo a fazer emergir um campo de embates e debates que acolham experiências e histórias diversas pelas quais os estudantes - crianças ou graduandos - possam dar sentido ao mundo. A aprendizagem não se reduz à transmissão de conteúdos, nem à imposição de verdades, mas a uma construção coletiva vozes possam ser ouvidas que dê visibilidade a grupos e sujeitos.

Estabelecendo essa política da diferença, compreendemos que o campo da educação de surdos e, principalmente um currículo de pedagogia bilíngue (Libras /LP) deve estar todo o tempo atento às especificidades do processo de desenvolvimento e aprendizagem dos sujeitos surdos, não entendendo que possuem alguma deficiência, mas que precisam ser olhados a partir de uma política linguística específica que os instrumentalizem, a partir da língua de sinais, a terem acesso aos bens culturais acumulados historicamente.

De acordo ainda com o documento que fundamenta nosso curso de pedagogia, apesar de alguns avanços legais ${ }^{2}$, ainda precisamos trilhar um longo caminho a fim de constituirmos novos modos de representação da surdez desvinculados da concepção médico terapêutica e, neste sentido, a formação de professores surdos

\footnotetext{
${ }^{2}$ Lei de LIBRAS no 10.436, de 24 de abril de 2002.
} 
e ouvintes que irão trabalhar com crianças surdas precisa atentar para esse fator primordial. Pois,

(...) diferentemente das crianças de comunidades de imigrantes ou indígenas, os surdos precisarão de modo crucial do mundo escolar para adquirirem uma língua mais acessível à constituição de suas subjetividades e identidades, que em geral, é a língua de sinais. Este já é um primeiro e importantíssimo compromisso das instituições escolares: promover projetos de aquisição de primeira língua. Ou seja, ao espaço escolar também caberá a educação linguística, além dos conteúdos curriculares da educação formal. E no caso das instituições de ensino superior, o compromisso de levar os futuros professores a refletirem sobre essa questão e contribuir para que estejam preparados para promoverem tais projetos. (PPC, DESU/INES: 2006.)

O saber/poder linguístico, principalmente nos contextos educacionais, tem posto a Língua Portuguesa como um ideal inalcançável na escola e, em consequência disto, temos visto gerações de sujeitos surdos destituídos de um lugar de acesso e participação na sociedade.

Diante disso, o que faz a escola? Acreditamos que a ela cabe o acesso dos alunos surdos à língua portuguesa em sua modalidade escrita, mas antes disso, há a necessidade da aquisição, por parte das crianças, de sua língua materna, ou sua L1, neste caso a Língua Brasileira de Sinais. "O letramento, na língua portuguesa, portanto é dependente da constituição de seu sentido na língua de sinais (...)" (Fernandes, p. 6).

O letramento visual é um processo que se inicia desde o princípio da vida do sujeito, quando são propiciadas a ele situações que o estimulem a adquirir um repertório cultural que garanta o seu compartilhamento dos bens culturais da sociedade.

Buscando garantir esses objetivos, planejamos nossas aulas de modo que as necessidades específicas do alunado surdo estivessem no centro das discussões em diálogo com as contribuições dos autores escolhidos. Difícil e desafiante tarefa! Como estabelecermos uma relação dialética entre autores que tratam da temática da surdez com aqueles que fazem parte de nossas áreas específicas de atuação, em nosso caso a Língua Portuguesa, a Literatura Infanto-juvenil e a Psicologia?

O eixo da disciplina "Cognição, corporeidade e contexto" foi a teoria histórico cultural de Vigotski, uma vez que compreende que a cognição e o desenvolvimento 
corporal e emocional do sujeito passam, obrigatoriamente, por uma troca com o meio, com o contexto sociocultural. Mais do que isso, Vigotski aposta que o sujeito é composto, pois unidades e não por dualidades. Neste sentido a unidade biológicocultural ou psiquismo-meio é indissociável, sendo impossível o desenvolvimento humano apartado de um contexto.

Escolhemos o que o autor fala sobre a brincadeira como atividade fundamental para o desenvolvimento psíquico da criança. A partir desse aporte teórico compreendemos que a brincadeira é a atividade principal da criança entre os 3 e 6 anos e que funciona como um agente de desenvolvimento, uma vez que é ela que possibilita à criança uma primeira experiência de separação entre o real e o abstrato. Em outras palavras, é quando a criança desvincula dos objetos seu sentido real (Ex. vassoura $=$ serve para varrer) $\mathrm{e}$ propõe outros sentidos possíveis (Ex. vassoura=cavalo), ela ensaia uma forma de pensar abstratamente. Também o mesmo ocorre com as ações. Ações comumente aceitas com um determinado sentido podem ganhar outros novos a partir da brincadeira.

Após os seis anos, a brincadeira ganha forma de jogos com regras, pois, nesta fase do desenvolvimento, são as regras que contribuem para as relações sociais e colaboram na lida com os sentimentos de fracasso, frustração e competitividade.

Vimos com Silva (2002) que para as crianças surdas o brincar ganha ainda um status especial, quando, objetivando a realização dos desejos infantis, proporciona a elas uma inserção, mesmo que simbólica, no mundo ouvinte. Em outras palavras, Silva (2002) com suas pesquisas sobre como brincam as crianças surdas evidenciou o fato de que, pelas brincadeiras, crianças surdas podiam realizar ações típicas de ouvintes - como falar ao telefone, por exemplo- e que segundo ela demonstram seu desejo por se inserirem na comunidade ouvinte.

Seguindo os objetivos da disciplina e do currículo, propusemos aos alunos a confecção de brinquedos e jogos ${ }^{3}$ que deveriam seguir um roteiro no qual os estudantes definiam para que faixa etária se destinavam, quais os objetivos e conteúdos abordados e a adequação às crianças surdas, portanto, deveriam ter em mente uma pedagogia visual.

\footnotetext{
${ }^{3}$ No próximo tópico serão descritos os materiais confeccionados.
} 
A disciplina "Textos e pretextos" se propôs a pensar que importância é dada à formação do leitor literário e ao papel da Literatura Infantil no desenvolvimento cultural da criança surda para além do recurso de ampliação de conhecimento de mundo, ou instrumento facilitador na aquisição de língua portuguesa como L2. O que se evidencia nas práticas escolares, sobretudo nas séries iniciais do primeiro e do segundo segmento do Ensino Fundamental, é que não há um contato significativo com a Literatura, ou, quando há, esse contato não se configura efetivamente como uma experiência cultural. Deve-se assegurar à criança que o texto literário tenha um tratamento distinto em relação aos outros, ou seja, que não seja banalizado, mas sim ressaltados sua relevância e seu significado. Negar isso à criança é vedar a oportunidade de desenvolvimento de sua criatividade.

Na Literatura Infantil, o lúdico tem papel fundamental como preparatório para o desenvolvimento do pensamento analítico, que permanece com o indivíduo ao longo da vida. A atividade de contar e recontar histórias permite que as crianças interajam no mundo simbólico e da fantasia, expressando opiniões, tornando-se agentes criativas e sujeitos questionadores e participativos. Dessa forma, a Literatura Infantil pode ser vista como promotora de recursos psicológicos que permitirão ações criativas, assim como o desenvolvimento da imaginação, ultrapassando a prática interativa que potencializa o desenvolvimento discursivo da criança.

Pensar a Literatura Infantil como instrumento de mediação para o desenvolvimento de uma criança ativa e crítica e refletir sobre as possibilidades de interação entre as crianças ainda são desafios para as salas de aula. O contato com a Literatura Infantil pode promover recursos psicológicos que permitirão à criança ações criativas e imaginativas, assim como construir sua personalidade e reconstruir sua visão de mundo. No entanto, as orientações expostas em diversos manuais de ensino e livros didáticos dão ênfase à utilização do texto literário como recurso de aquisição, ampliação e fixação de vocabulário, sem destacar a literatura como ferramenta de desenvolvimento do potencial criativo. O que se evidencia nas práticas de leitura literária das escolas é a tensão existente entre o saber literário e o ideal pedagógico; no entanto, não é tarefa simples delimitar em que medida se dá o uso da literatura a serviço da pedagogia. 
Em se tratando da escolarização de crianças surdas, há ainda um agravante acrescido à apatia com que as escolas tratam o texto literário, que é a falta de material adequado às suas necessidades de compreensão.

Os alunos surdos necessitam de uma pedagogia valorativa de aspectos visuoespaciais de aprendizagem e a escassez de materiais didáticos, conforme já dito, e a carência de obras literárias voltadas ou adaptadas para o público surdo, como, por exemplo, produções imagéticas e cinematográficas de fábulas e outros gêneros literários, é um entrave ao desenvolvimento do aprendiz. Em sua fase de escolarização, grande parte das crianças surdas não tem contato com textos literários ou isso ocorre por meio de textos em língua portuguesa sem os requisitos imagéticos próprios para que elas compreendam o significado do texto. Por isso a necessidade de uma produção literária imagética que possibilite, por meio da visualidade, o contato com o universo literário, por textos em prosa (novelas, contos, crônica, memórias, biografias e teatro) e em verso (poemas, cantigas, parlendas, adivinhas), uma vez que para a criança surda a apropriação dos significados não se dá de forma direta pelos órgãos dos sentidos, mas por meio de práticas imagéticas mediadas pela presença dos signos.

É necessário legitimar a inserção da criança surda na cultura letrada desde o início de sua escolarização, e garantir que outros bens culturais diversificados Ihes sejam apresentados como forma de desenvolver a prática e compreensão da leitura. O contato com culturas externas à comunidade surda permite a ampliação e ressignificação de conceitos por parte da criança surda, e a Literatura é um bem cultural capaz de desenvolver nela tais fatores. No entanto, o desenvolvimento de competências e habilidades importantes que garantam à criança surda autonomia para fazer da leitura literária fonte de fruição e reelaboração da realidade e ampliação de conhecimentos depende de alguns fatores.

O contato com a literatura infantil, seja por meio das narrativas dos clássicos universais ou outros gêneros, deve ser pensado como possibilidade de inclusão cultural, e isso implica considerar as especificidades de recepção da criança surda. Esta, se alfabetizada em sua primeira língua, Libras, poderá ser leitora de livros de textos literários em sua segunda língua, a Língua Portuguesa. Isso requer processos específicos para que a prática de leitura, tanto em Libras quanto em Língua 
Portuguesa, seja significativa e proporcione à criança surda desenvolver a criatividade e imaginação, assim como atribuir sentido ao texto que lê.

\section{A vivência dos estudantes-pesquisadores}

O envolvimento dos alunos nessa atividade foi visível. A vontade de experimentar na prática os conceitos trabalhados em sala demonstrava a necessidade que os estudantes de pedagogia têm em ter o contato com a prática, aplicando seus conhecimentos e aprendizagens para além dos momentos de estágio. Embora alguns alunos já fossem professores e, portanto, atuassem em sala de aula, o desejo de experimentar as atividades planejadas e conferir a resposta das crianças foi observado em todos.

Algumas questões eram antecipadas em nossos debates. No que tange à questão da literatura, nos perguntávamos, que recursos pedagógicos seriam necessários para o sucesso da formação de leitores literários surdos? Esta questão não se esgotaria apenas naquela disciplina do currículo de Pedagogia e também não encontra solução única, mas depende de práticas conjugadas a políticas públicas de acessibilidade que eliminem barreiras para a plena participação dos alunos surdos, considerando suas necessidades específicas.

Partindo desse princípio, os alunos da disciplina "Textos e Pretextos" e "Cognição, corporeidade e contexto" se propuseram a pesquisar e elaborar materiais pedagógicos adequados a crianças surdas no Ensino Fundamental 1, entre 6 e 10 anos, em fase de aquisição de Língua de Sinais, como forma de abordar/apresentar a literatura infantil pensando em uma prática para sala de aula. As atividades deveriam ser lúdicas, buscando despertar a interação, criatividade e a imaginação da criança. Imediatamente surgiram as mais diferentes propostas, como teatro de fantoche ou objetos, tapete de contação de história infantil, animação, dramatização de história infantil, atividade de desenho a partir de uma história infantil, jogos, baú de histórias infantis, pescaria ecológica, jogo de trilha, etc.

Para que as brincadeiras e atividades planejadas fossem pensadas com cuidado, buscando atender as especificidades do público-alvo, propusemos que os estudantes desenvolvessem, inicialmente um roteiro pensando nas crianças que 
fariam parte das atividades, a faixa etária, fase do desenvolvimento/aquisição da Libras, no ambiente em que se desenvolveriam as atividades e nos objetivos das atividades tendo, assim, como foco:

a) O público: quem são os alunos e qual a faixa etária e o ano de escolaridade? São crianças surdas que já adquiriram Libras? Têm uma segunda língua (LP2)?

b) O objetivo: que tipo de interação você busca com essa atividade? O que essa atividade vai propiciar à criança?

c) O espaço: a atividade será realizada em sala de aula? Você precisará de outro espaço? Você precisará de quais recursos (computador, televisão, projetor, objetos variados, materiais variados como papel, tesoura, etc.)

Dessa forma, cada grupo elaborava junto com seu brinquedo/atividade um planejamento em forma de roteiro que seria o guia e o fundamento teórico das atividades.

No dia combinado com o Professor orientador do Setor de Ensino Fundamental 1, fomos com os alunos fazer a apresentação das atividades para as crianças entre 6 e 10 anos. Foram várias atividades, bem lúdicas e dinâmicas envolvendo diferentes linguagens - vídeos, desenhos, teatro - e abordando os objetivos destacados (i)reconhecer a importância da leitura literária na formação da criança surda (ii) identificar a brincadeira como possibilitadora de desenvolvimento. Percebemos uma ótima aceitação das crianças que participaram, interagiram e criaram novas situações de aprendizagem na relação com os estudantes de pedagogia. Estes, por sua vez, se empenharam bastante na organização das atividades e souberam bem como lidar com os imprevistos e situações novas. Foi uma manhã bastante proveitosa e prazerosa para todos!

\section{Conclusão}

O objetivo central deste artigo foi fazermos um relato de experiência de duas professoras do DESU/ INES que se propuseram a oportunizar aos estudantes a vivência da prática educacional e, ao mesmo tempo, refletir sobre ela, trabalhando 
com conhecimentos teórico-práticos. Partimos do princípio de que a ação e a reflexão compõem uma relação dialógica e dialética.

Com o desenrolar dessa experiência esse princípio se tornou ainda mais claro para nós ao percebermos o quanto essas situações podem ser enriquecedoras para os alunos de Pedagogia. Muitas são as queixas e críticas de alunos que se dizem 'sem a prática' ao terminar a faculdade e não habilitados para assumir a regência de uma turma de crianças, mesmo portando diploma de pedagogos. A imersão em situações de sala de aula torna-se, a nosso ver, uma estratégia que deveria fazer parte, com destaque, de nosso currículo e planejamento. Esse seria o começo de uma formação de pedagogos reflexivos, ou seja, que se tornam capazes de fazer e pensar sobre o fazer. Pedagogos-professores-reflexivos seriam aqueles que estão constantemente refletindo sobre a prática a partir das lentes das teorias que os ajudariam a enxergar esse cotidiano de forma mais apurada e arguta.

A atividade docente deve ser algo que vai além da transmissão de conhecimento e da descrição do que observamos em sala de aula, mas também aprender a refletir sobre as práticas cotidianas. De acordo com Maturana e Varela (2007, pp. 29-30): "descrever uma ação não é o mesmo que refletir sobre a mesma, embora a descrição seja um componente da reflexão, 'um processo de conhecer como conhecemos, um ato de nos voltarmos sobre nós mesmos, é a única oportunidade que temos de descobrir nossas cegueiras".

Assim podemos dizer que nós enquanto professoras do curso de Pedagogia, buscamos essa reflexão, essa prática reflexiva ao mesmo tempo em que despertávamos nos estudante a importância ou mesmo a necessidade da reflexividade em sua formação.

\section{Referências Bibliográficas}

INSTITUTO NACIONAL DE EDUCAÇÃO DE SURDOS. Opção pela transformação do Curso Normal Superior, Licenciatura, do Instituto Nacional de Educação de Surdos em Curso Bilíngue de Pedagogia, Licenciatura. Rio de Janeiro: DESU/INES, 2006.

FERNANDES, S. F. Práticas de letramento na educação bilíngue para surdos. Curitiba: SEED, 2006. 
GIROUX, H \& SIMON, R. Cultura popular e pedagogia crítica: a vida cotidiana como base para o conhecimento curricular. In: MOREIRA, A. F. \& SILVA, T. T. (orgs) Currículo, cultura e sociedade. São Paulo: Cortez, 2013.

MATURANA 'H. R. e VARELA, F. A árvore do conhecimento: as bases biológicas da compreensão humana. São Paulo: Palas Athena, 2007.

SILVA, D.N.H. Como brincam as crianças surdas. São Paulo: Plexus, 2002

VIGOTSKI, L.S. A brincadeira e seu papel no desenvolvimento psíquico da criança. Revista Virtual de Gestão de Iniciativas Sociais. v.11, 2008.

ZACCUR, E. A pesquisa como eixo da formação docente. In: ESTEBAN, M.T \& ZACCUR, E. (orgs) Professora pesquisadora: uma práxis em construção. Rio de Janeiro: DP\&A, 2002.

\footnotetext{
Sobre as autoras

Aline Xavier

Doutora em Literatura Comparada pela UERJ, Mestre em Literatura Brasileira e graduada em Letras pela mesma Universidade. Profa. Adjunta de Língua Portuguesa como L2 no Departamento de Ensino Superior - INES. Desde 2015, vem pesquisando sobre o papel imaginativo na infância e o papel da literatura no desenvolvimento cultural da criança surda.

\section{Maria Carmen Euler Torres}

Possui graduação em Psicologia pela Universidade Federal Fluminense (1998), mestrado em Educação pela Universidade Federal Fluminense (2002) e doutorado em Psicologia pela Universidade Federal do Rio de Janeiro (2009). Atualmente é professora de Psicologia do Departamento de Ensino Superior do Instituto Nacional de Educação de Surdos (DESU/INES) onde oferece as disciplinas Psicologia e Educação I e II. É líder de Grupo de Pesquisa " Criança surda: cultura e linguagem", onde investiga a importância da brincadeira no desenvolvimento psíquico da criança surda. Também lidera o grupo de extensão " Legendagem e acessibilidade" que tem por objetivo legendar filmes nacionais para estudantes surdos e promover cursos e debates na área da acessibilidade.
} 